come before children and children before grandchildren; and possibly also in its spatial representation in the falling of spirits from above in a succession of descents at points in time. But it is also explicit in Nuer statements of the order in which their various spirits appeared among them. God was always there, then at various points of time the spirits of the air, the totemic spirits, and the sprites appeared on the scene, the fetishes being the most recent arrivals.

Spirit is thus conceived of by the Nuer, through their configurations of symbolic representations, as outside their social order, a transcendental being; but also as in their social order, an immanent being figured in all sorts of representations in relation to their social life and events of significance for it. Nuer go up and down the scale of these conceptions, speaking sometimes of God in a general sense as ubiquitous Spirit; sometimes in a more definite and distinctive way as Spirit who is in the sky, the creator, and the father; and sometimes in terms of one or other of his refractions.

These refractions correspond, as we have noted, with different levels of social activity, but it would be a mistake to leave the matter there, for an interpretation in terms of social structure merely shows us how the idea of Spirit takes various forms corresponding to departments of social life, and it does not enable us to understand any better the intrinsic nature of the idea itself. The varying degrees. of immanence in which the conception is expressed show us that the different social levels at which Spirit is manifested are also different degrees of religious perception. Spirit is sometimes perceived, intellectually and intuitively, as one, transcenderital, pure Spirit and at other times, in relation to human affairs and interests, as one or other of a great number of figures through which it is made known, in varying degrees of materialization, concretely to human intelligence. Nor is it, even with strict reference to a purely structural interpretation of the conception of Spirit in Nuer society, simply a matter of social levels, for, as we have seen, God is also experienced unrefracted at all levels, down to the individual; so that a structural interpretation explains only certain characteristics of the refractions and not the idea of Spirit in itself, which requires separate consideration. Here I have only tried to show that, and how, the conception of Spirit is broken up by the refracting surfaces of nature, of society, of culture, and of historical experience.

UNIVERSITY OF OXFORD

OXFORD, ENGLAND

\section{Yap Kinship Terminology and Kin Grodps*}

\section{By DAVID M. SCHNEIDER}

VY INTENTION here is to report the kinship terminology of Yap and to outline a relatively unusual set of devices governing the employment of these kinship terms. I will therefore go only so far into an analysis as will show that the terminological system; taken in conjuction with what I will call the "rules of reference," is congruent with the kinship groupings and the way they are structured.

The analysis of any concrete system necessarily raises certain theoretical problems. The Yap kinship system depends heavily on the rarely described device which Kroeber (1909, p. 79) called "the condition of life of the person through whom relationship exists" and Murdock (1949, p. 106) recently modified and called "decedence." I believe this is the first extended account of how this device works in a particular kinship system.

A second major problem arises directly from this description. In the Yap system the device of "the condition of life of the person through whom relationship exists" appears to integrate two otherwise incompatible structural elements: a strongly emphasized nuclear family set in a matrix of an equally strongly emphasized lineage. The analysis of the functions of "the condition of life..." device depends to a great extent on the hypothesis that the nuclear family and the lineage are organized about inherently incompatible principles.

The third major problem, which cannot be treated at length here, is that of the stability of systems composed of inherently contradictory elements. The implication of the analysis which follows is that in any system the apparent contradiction of elements is less important for stability than the nature and efficacy of the integrative devices. Crow type cousin terminology, for instance, can exist in stable equilibrium with patrilineal kin groups, as is the case in Yap, when integrative devices such as "the rules of reference..." bind them together in a smoothly working system. The assumption that their combination within the same kinship system is necessarily unstable is, to my mind, untenable.

The culture of the Micronesian island of Yap in the Western Caroline Islands is characterized by a primary concern with political activity and a correlative subordination of kinship. More than one hundred villages are organized into eight districts grouped into three alliances. Each alliance is headed by the chief of the highest ranking village in the leading district within the alliance. Cross-cutting this organization is a nine class system sub-divided

* This report is based on field work for the Peabody Museum of Harvard University and the Coordinated Investigation of Micronesian Anthropology sponsored by the Pacific Science Board of the National Research Council from October 1947 to June 1948. 
into two "castes," and superimposed on this is a war organization of two traditionally opposed sides, each composed of two of the top four classes, and each side supported by allies from the lower classes. Yap is a highly stratified society.

KIN GROUPS

1. The tabinau: A village (binau, land) is made up of an aggregate of kin groups, each of which is called tabinau (people of the land). The tabinau within a village are sometimes affiliated by affinal or consanguineal bonds, but when tabinau happen to be so related, this relationship is treated as fortuitous. The village is a political unit conceived in geographical terms; it is not a single kin group.

Although Yap conception defines this kin group as those persons who share an attachment to a given plot of land, we may usefully define tabinau membership in terms of residence and descent, and still deal with the same group.

Membership in the tabinau is determined by patrilineal descent, and in the case of married women, by patrilocal residence as well. The members of a tabinau are a man and his wife, their married sons and the sons' wives, married daughters living elsewhere, and all unmarried sons, daughters and patrilineally related grandchildren. Thus the tabinau contains a patrilocal extended family, its constituent nuclear families and a patrilineage. Every married woman is necessarily a member of two tabinau: that of her birth and her tabinau by marriage.

Land is nominally owned by the oldest male member of the tabinau (the leader of the tabinau) and the inheritance of land, status (magician, chief, etc.), rank, and valuables (machaf, so-called Yap money) flows along patrilineage lines. Only in the absence of patrilineage members do women of the patrilocal extended family inherit. Land use, as distinct from land ownership, is allocated to constituent nuclear families.

The tabinau is so organized that it constitutes a corporate group primarily in its formal relations with other tabinau. The status of leader of the tabinau (suon e tabinau), filled by the oldest male, functions only with respect to other tabinau or to the village as a whole or to the body of tabinau ghosts. The leader of the tabinau is the articulating status in the structure of relationships between the tabinau which make up a village. Within each tabinau, all relationships are defined in nuclear family terms; that is, as husband-wife, father-son, brother-sister, etc. The man who acts as "leader" in the external relations of the tabinau as a group acts as "father" in its internal affairs.

The relatively low level of solidarity which the tabinau shows is congruent with this organization.'The unit of maximal solidarity is the nuclear family, and the strongest links are those between father-son and sibling-sibling.

The nuclear family may be described as "discrete," since it occupies a house of its own apart from other dwellings; it produces, processes, and con- sumes its own food and almost all of its own materials from land allocated to its own special use; and makes no special effort to cooperate with other nuclear families within the tabinau except where tasks are impossible for one nuclear family alone, or where the tabinau must act as a corporate unit vis-à-vis other tabinau or the village as a whole.

The internal structure of the tabinau is thus one where a series of discrete nuclear families are related patrilineally, each nuclear family relating to the next by the father-son or brother-brother bond, and each ranked for purposes of authority, inheritance and succession by the relative age of the adult male members. Formal relations between constituent nuclear families flow from elder to younger brother, and from father to the eldest tabinau member who is a "son" (own son and deceased brothers' sons). Branching out from these core relationships are the out-marrying women and the affinal bonds through them, and the affinal bonds through the wives in the tabinau.

II. The genung: In addition to his membership in a patrilineal group, every Yap is also a member of a named exogamous matrilineal clan, the genung. Each matrilineal clan has a place of origin, and a place sacred to it where magical observances intimately associated with the clan may be carried on. Otherwise it is without local affiliation. Where members of a tabinau are necessarily of one village and of one class within one "caste" (since one tabinau is confined to plots of land within one village and each village as a whole occupies a place within the "caste" system), members of a given clan are scattered over the island, throughout the class and "caste" system, and in various villages and districts. Even the sacred place of the genung is in the hands of the tabinau whose leaders owns it, and the status of magician to the clan is often occupied by a man from another clan by virtue of the rule of patrilineal inheritance and succession.

The functions of the matrilineal clan are first, regulation of marriage by the rule of exogamy; second, provision for sanctuary in time of war and hospitality in time of peace; and third, the provision of a widely extended group of last resort in borrowing valuables, promoting political ties, and begging favors of diverse sorts.

It is significant that the individual's affiliation with a particular clan falls within the domain of personal matters and is not openly discussed, nor is it permissible to make direct inquiry. A mother is expected to tell her child of his clan affiliation, to point out other children who are members of the same clan, and to warn the child against sexual relations with members of his own clan. Beyond this the individual's membership in a particular clan is treated as a secret.

DESCENT

Today, all of the older people and most of the younger people of Yap regard paternity as a purely social fact, not a biological relationship; coitus is believed irrelevant to conception. Hence affiliation with a tabinau is conceived 
as a social relationship, not one of biological descent. Affiliation with the genung, on the other hand, is viewed as a concrete biological relationship.

The rules governing adoption will make this situation clear. Adoption is permitted when the child to be adopted is not the mother's first child, and when all arrangements have been completed before the birth of the child. Once a child has been born without adoption arrangements being made, it cannot be adopted. An adopted child belongs to the tabinau of its adopting parents and terminates its affiliation with the tabinau into which it was born. The child's genung affiliation is more complex. The child becomes completely affliated with the genung of its adoptive mother. It also retains its affiliation with the food and exogamy taboos and name of the genung of its real mother, but has no affiliation with the people of that name. Thus for purposes of marriage, the adopted person may marry no one of his adoptive mother's matrilineal clan nor of his real mother's matrilineal clan. An adopted woman transmits to her children only the affiliation with her adoptive mother's genung; she does not transmit the genung affiliation of her real mother.

\section{MARRIAGE}

Marriage is patrilocal, and may be celebrated by a simple ceremony a onth or two after the couple has settled in their own quarters. They occupy a house which is owned by the groom's father, but is built apart from the groom's parents' residence. The marriage ceremony involves an exchange of Yap money and food between the nuclear families concerned and may be followed at a later date by the ritual transfer of cooking privileges from the groom's mother to the wife. The ceremony, and indeed marriage itself, is conceived as a relationship between two nuclear families. Neither the tabinau nor the clan figure in the ceremony. The marriage ceremony is frequently omitted, and even when it is held it is treated lightly and with only a minimum of formality.

Marriage rules consist in patrilineage and clan exogamy, the prohibition on marriage of a couple sharing one grandparent, the prohibition on cross-"caste" marriage, and the generalized preference for unions in which the parties are of the same or adjacent classes, with the tendency for women to marry class equals or one class above, men to marry class equals or one class below their own level. Couples tend to come from the same or nearby villages.

Polygyny is permitted with the consent of the first wife. This permission is seldom granted and so monogamy is almost universal except in cases where leviratic marriage (widow inheritance) takes place. Here permission of the first wife need not be obtained, nor is she permitted to object to this arrangement. Although the levirate is not compulsory, it is preferred. The parties concerned are, of course, the widow and the oldest surviving brother of the deceased. The sororate is unknown, as is polyandry. ${ }^{1}$
Divorce is simple and unadorned by ceremony. It is frequent among childless couples, rare after the first surviving child.

\section{KINSHIP TERMINOLOGY}

The list of kinship terms which follows is joined with a list of relatives. This constitutes a classification of kin into categories. It does not constitute a list of terms of address, since terminology is used only referentially. But the list also includes some terms which are never used referentially by certain kin under certain circumstances. These latter are nevertheless kinship terms in the sense that they are the rubrics under which certain relatives are classified. To put it operationally, if one asks, "What is the word for . . . ?" one receives the answer recorded here, although this term may never be employed referentially (or vocatively) so long as certain conditions prevail.

\begin{tabular}{|c|c|}
\hline YAP KINSHIP TERM* & Kin Classified \\
\hline citimongog & $\mathrm{Fa} ; \mathrm{FaBr}$; MoSiHu; FaSiHu; FaSiSo; $\mathrm{SpFa}$; $\mathrm{SpFaBr}$. \\
\hline citiningog & Mo; MoSi; FaBrWi; FaSi; FaSiDa; SpMo; SpMoSi. \\
\hline fakag & $\mathrm{Ch} ; \mathrm{BrCh} ; \mathrm{MoBrCh} ; \mathrm{MoSiChCh} ; \mathrm{FaBrChCh} ; \mathrm{FaSiChChCh}$ \\
\hline & $\begin{array}{l}\text { SiChCh; (Woman Speaking) SiCh. Also used as any animate } \\
\text { possessive. }\end{array}$ \\
\hline wolageg & $\begin{array}{l}\text { Sib; } \mathrm{FaBrCh} ; \mathrm{MoSiCh} ; \mathrm{FaSiChCh} \text {; and all members of own } \\
\text { sib not otherwise related. }\end{array}$ \\
\hline ngani & Older sib. \\
\hline wain & Younger sib. \\
\hline ngayil & Siblings born of the same mother. ${ }^{* *}$ \\
\hline W'engog. & MoBr; MoBrWi; (Man Speaking) SiCh. \\
\hline gidi ni m'fen & $\mathrm{FaSiCh} . * * *$ \\
\hline utu & $\mathrm{FaFa}$; MoFa; FaFaBr; MoFaBr; SpFaFa; SpMoFa. \\
\hline oilau & FaMo; MoMo; FaFaSi; MoFaSi; SpFaMo; SpMoMo. \\
\hline ungin & $\mathrm{ChCh}$; BrChCh; FaBrChChCh; MoSiChChCh; MoBrDaCh. \\
\hline mugurl & The children of all tungin. \\
\hline le'engog (or figuringog) & $\begin{array}{l}\text { Sp; spouses of siblings of same sex as speaker; siblings of } \\
\text { spouse who are of same sex as spouse. }\end{array}$ \\
\hline enungog & (Woman speaking) BrWi; HuSi. \\
\hline wec'Ama & All relatives by marriage. \\
\hline uguru: & Plural wives. \\
\hline
\end{tabular}

* Terms are given in the dialect of rumung. Orthography is as follows where it is different from English: $\mathrm{c}$ is ch as in child, a is the vowel sound of "calm," A is the vowel sound of "sat"; ' is the glottal stop; a colon : indicates a long vowel; an underlined vowel, $u$ for instance, is a short vowel; $\mathrm{d}$ is the voiced th as in "this."

** The term ngayil, siblings born of the same mother, is a contraction of two words meaning "same belly."

*** gidi ni m'fen means "people who chase away." 
EMPLOYMENT OF KINSFIP TERMS: THE RULES OF REFERENCE

The following ten rules govern the use of kinship terms. Because of rule (1), I will refer to these as "The Rules of Reference."

(1) Kinship terms are used in reference, almost never as direct forms of address. Exceptions to this rule occur in rare jokes and in certain ritual contexts. Kinsmen are addressed by their personal names.

(2) As long as ego's father ${ }^{2}$ is alive he alone is referred to by the term for father and he alone plays the role defined for that status. When ego's own father dies, his oldest surviving brother, or lacking a father's brother, ego's oldest brother, or lacking an older brother, any adult male who falls within the terminological category of father, in that order, replaces the father and assumes the role of father, and except for ego's older brother, is referred to by the term for father. So too, reciprocally, only own children are referred to as "my child" except ${ }^{3}$ when ego's brother's death has shifted the children's referent for the term father from their own father to ego.

The role of father centers on authority and responsibility, the child reciprocates with respect and obedience. The father is responsible for providing food and care for his child, for the trouble the child may get into, and for obtaining such supernatural assistance as the child may need.

In diagram IA below, the children 4 refer to the man 1 as father and the children 5 refer to the man 2 as father. Man 1 plays the role of father toward children 4 , but not 5 , while father 2 plays the role of father toward children 5 but not 4 . In the adjacent diagram, IB, the man 1 has died and been replaced by his oldest surviving brother, 2 . It is at this time and not before that the children 4 refer to 2 as father and he refers to them as my child. It is at this time and not before that 2 commences to act in the role of father toward children 4, and they in turn begin to act in the child's role toward their new father. Man 3, it will be noted, the youngest brother in the parental generation, is not referred to as father by children 4 or 5 so long as his older brothers

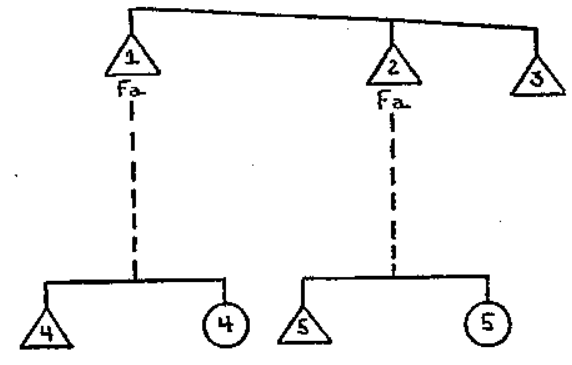

A

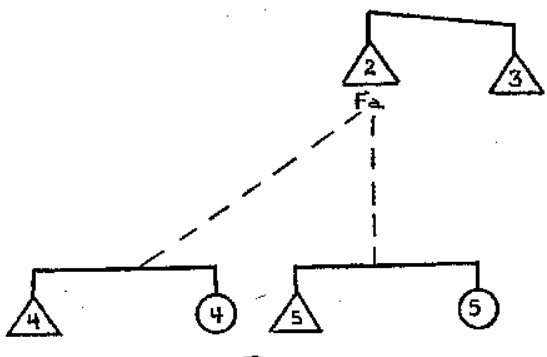

Q
DIAGRAM I are alive. Should he survive both his brothers (1 and 2), he will become "father" to children 4 and 5 .

(3) As long as ego's real mother is alive and married to the man ego refers to as father, she alone is referred to as mother, and she alone plays the role of mother toward ego. If, through divorce or death, ego's real mother is no longer married to ego's father, and if he has not remarried, ego's real mother continues to be referred to as mother. If ego's father has remarried, the new wife is referred to as mother, she plays the role of mother toward ego, and ego may not refer to the divorced or dead woman as mother. So too, reciprocally, for "my child" when ego is a woman.

The role of the mother is like the role of the father in that both are defined primarily in terms of authority and responsibility, but the mother is warmer and more affectionate toward her children than the father is. From the point of view of the child, however, both father and mother merit respect and obedience, although these are tempered somewhat toward the mother commensurate with the warmth and affection she shows.

In diagram IIA below, the normal reference with respect to real mother is shown; the children 3 refer to woman 5 as mother. In diagram IIB, real mother 5 of children 3 is divorced and father 1 has remarried, and is now married to woman 7 . Children 3 refer to woman 7 as mother and no longer refer to woman 5 as mother. Note that the father's sister and father's brother's wife, although classified as mother, are not referred to by that kinship term.
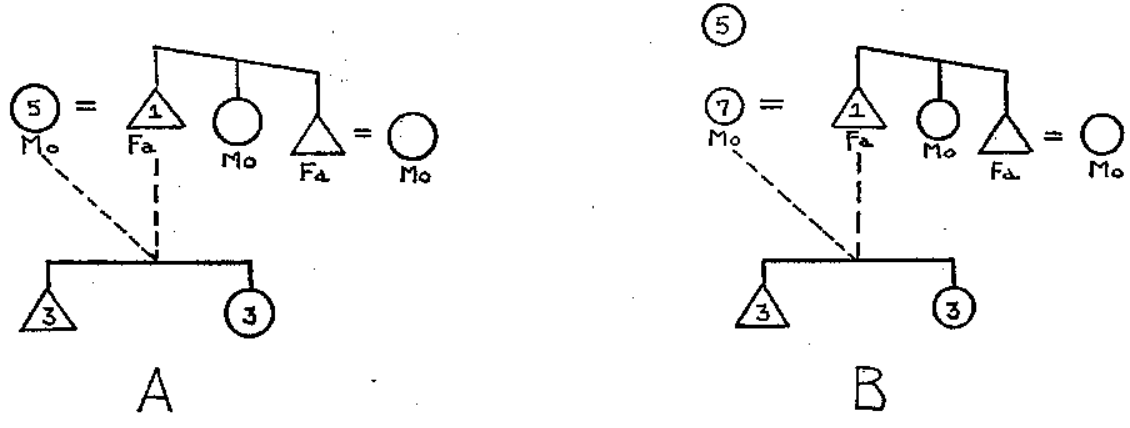

$\mathrm{B}$

Diagram II

(4) If on the death of ego's father, father's oldest surviving brother becomes the husband of ego's widowed mother, ego's mother alone, and not ego's father's brother's wife is referred to as mother and she alone plays the mother's role. But if, on the death of her husband, ego's mother declines to elect the levirate and goes home instead, in divorce, ego ceases to refer to her as mother and instead refers to his father's brother's wife alone as mother, and she will play the mother's role toward ego. 
It should be noted, with respect to rules 3 and 4 above, that when ego's real mother is divorced from father and so may not be referred to as mother and may not play the mother's role, ego may, at his own option, maintain the role of child by bringing her gifts, particularly of food, and so in fact maintain the relationship of child to mother. When a child maintains such a relationship with the real mother, this relationship has no legal standing. This same situation obtains in the case of an adopted child; he may if he wishes bring his real parents gifts from time to time, and continue to recognize them as his parents, although this recognition is not formally sanctioned. By maintaining this relationship with his real parents, ego does not lose his position with respect to inheritance or succession in his adoptive family, nor does he regain his lost position with respect to inheritance or succession from his real parents. If, however, his real father is the last member of his patrilineage, an adopted child may establish a claim superior to that of distant collaterals or affinals if and only if he has maintained an informal child-parent relationship with his real parents after having been adopted into another family.

(5) As long as ego's father is alive, only ego's real siblings (children of the same father) are referred to by the terms for siblings and only they act in the role of sibling toward each other. On father's death, however, ego's real siblings plus the children of the man whom ego now refers to as father (the eldest among father's surviving brothers) are included in the reference and play the appropriate role. The children of any other living father's brothers are not included and these other living father's brothers are not referred to as father.

Older siblings are distinguished terminologically from younger, although compound terms must be employed if they are to be distinguished on the basis of their sex. Siblings should stand together and help each other. There is a mild avoidance relationship between brother and sister which if anyting enhances the solidarity of the pair. Older brother is described as "like a father" while younger brother is "like a son." In childhood, older siblings are given the care of younger siblings and they are vested with a good deal of authority over younger siblings throughout their lives.

(6) The term spouse is used to refer to that person of opposite sex with whom a marriage relationship obtains. Although ego's older brother's wife is classified as spouse, ego is prohibited from referring to her by that term because, it is said, "older brother's wife is like a mother." Ego's older brother is "like a father" and has parental rights and obligations toward ego; hence ego's older brother's wife is "like a mother." It is permissible but held to be in very poor taste for older brother's wife to refer to her husband's younger brother as spouse, and this use of the term is probably never employed when husband's younger brother is adult or mature, as it would suggest a sexual relationship between them, which is prohibited. Older brother's wife may use the term for spouse with reference to her husband's younger brother if the latter is but a child, at which time its use is regarded as a joke.
(7) Only the brother of the woman currently referred to as mother is classified as mother's brother, hence mother's brother ceases to be referred to as such when mother is divorced from father. If, however, real mother died while married to father, both mother's brother by the dead mother and mother's brother by the current wife of father are referred to as mother's brother. The situation is similar for sister's child, classified under the same term as mother's brother, so that sister's child by her current husband, not her former divorced husband, is referred to as sister's child.

Mother's brother is described as being "like an older brother"; that is, he stands midway between the status of parent and sibling. Essentially a member of the parental generation, he is yet treated as a member of the sibling group. Friendliness, guidance, confidence may occur between mother's brother and sister's child (irrespective of sex), yet the relationship is not equalitarian by any means. The mother's brother is that combination of father and brother which lacks the father's authority and the brother's intimancy, but contains the father's guidance and the brother's solidarity.

(8) All who are classified within the categories of grandfather and grandmother are referred to by the appropriate kinship term and all, along with ego, act in the kinship roles appropriate to their positions. Similarly, all who may refer to ego as grandfather or grandmother are in turn referred to as grandchildren.

The relationship of grandparent to grandchild is warm and intimate and a child who feels mistreated by his parents may flee to his grandparents, who will protect him.

(9) Although classified as mother, father's sister is treated with special respect distinct from that accorded mother, and is referred to as "father's sister" or by her personal name, never as "mother." Father's sister's son and father's sister's daughter, classified as father and mother respectively, are never referred to by those terms, but by another collective term, gidi $n i \mathrm{~m}^{\prime} \mathrm{fen}$, and are always treated with great respect.

The term gidi ni m'fen means literally "people who chase away"; it is neither an elementary nor a compound kinship term. The phrase refers to the right of the father's sister's children to chase ego off his land either for failing to accord them the deep respect which is their due or for committing some very serious breach of custom. The fact that the only occasions on which these rights were exercised occurred so far in the past as to have become myths believed as real events does not in any way minimize the seriousness with which these rights are treated.

(10) Those persons who are classified but not referred to as father, mother, sibling, spouse or my child are (except as specified in rules 6 and 9 above) referred to by their personal names alone and without kinship designation, and are treated as kinsmen, but without further differentiation except for age and sex. Thus two old men, one of whom is classified but not referred to as 
father, one classified but not referred to as sibling, are both treated as kinsmen as distinguished from non-kin, and with reference to their age and sex status, but without further differentation.

\section{ANALYSIS}

It follows from rules $2-10$ that kinship terms are used only when the rules defined as appropriate to them are played. When kinship can be traced, but the term for the particular relative is not employed, that relative is treated as a kinsman, as distinguished from someone who is unrelated, and of a particular age and sex category.

When two persons play the prescribed kinship roles and employ the terms appropriate to their relationship, I will call the relationship an active one. When two persons trace a kinship relationship but do not employ the terms or play the appropriate roles, I will call the relationship inactive. Rules $2-8$ designate the conditions under which a relationship may be active or inactive.

Certain relationships remain inactive and never become active. Certain others, however, are likely to change from inactive to active, and these I will call potentially active. ${ }^{4}$

Table I summarizes the data contained in rules $2-10$ in terms of the distinctions between active, potentially active and inactive relationships.

It will be recalled that the tabinau is internally organized as a ranked series of nuclear families, each joined with the other through the father-son or brother-brother bond. In an important sense there is no such unit as ego's own tabinau since the tabinau becomes a unit only in its relations with other tabinau, and in these relations it is ordinarily the leader of the tabinau alone who acts on its behalf. Primarily the tabinau is defined by the outsiders' treatment of it as a unit. ${ }^{5}$ From ego's perspective only nuclear family relationships obtain between him and other members of his tabinau. Congruently, there is almost none of that kind of solidarity in which each member identifies with a common group symbol, and each relationship of one member with another has as one important element the fact of common group membership. In Yap, the individual's identity in his tabinau is almost exclusively his nuclear family status-that is, he act exclusively as a father, mother, brother, sister, son, daughter, husband or wife, almost never as an otherwise undifferentiated tabinau member-so far as the relationships of members of the same tabinau with each other are concerned.

The groupings of kin according to the terminology alone do not correspond with this mode of tabinau structure in two respects. First, the terminological categories spread across tabinau boundaries, so that the terminological categories fail to segregate this kin group. Second, there is no terminological reflection of the importance or discreteness of the nuclear family or of the primacy of nuclear family relationships.
TABLE I

\begin{tabular}{|c|c|c|c|}
\hline & Active & $\begin{array}{c}\text { Potentially } \\
\text { Active }\end{array}$ & Inactive \\
\hline $\begin{array}{r}\text { cilimongog } \\
\text { (father) }\end{array}$ & own $\mathrm{Fa}$ & $\mathrm{FaBr}$ & MoSiHu; FaSiHu; FaSiSo* \\
\hline $\begin{array}{l}\text { citiningog } \\
\text { (mother) }\end{array}$ & own Mo & $\mathrm{FaBrWi}$ & MoSi FaSi; ${ }^{* *}$ FaSiDa* \\
\hline $\begin{array}{l}\text { wolageg } \\
\quad \text { (sibling) }\end{array}$ & own Sib & $\mathrm{FaBrCh}$ & MoSiCh; FaSiChCh \\
\hline $\begin{array}{l}\text { le'engog } \\
\quad \text { (spouse) }\end{array}$ & own Sp & $\begin{array}{l}\mathrm{BrWi} \\
\mathrm{HuBr}\end{array}$ & $\begin{array}{l}\text { WiSi } \\
\text { SiHu }\end{array}$ \\
\hline $\begin{array}{l}\text { fakag } \\
\qquad \text { (child) }\end{array}$ & own $\mathrm{Ch}$ & $\begin{array}{l}\mathrm{BrCh} \\
\mathrm{FaBrSoCh}\end{array}$ & $\begin{array}{l}\mathrm{MoBrCh} ; \mathrm{MoSiChCh} \\
\mathrm{SiChCh}^{*} \mathrm{FaSiChChCh}\end{array}$ \\
\hline $\begin{array}{l}\text { tutu } \\
\text { (grandfather) }\end{array}$ & $\begin{array}{l}\text { own } \mathrm{FaFa} \\
\text { own } \mathrm{MoFa}\end{array}$ & $\mathrm{FaFaBr}$ & MoFaBr; FaMoBr; MoMoBr \\
\hline $\begin{array}{l}\text { toitau } \\
\text { (grandmother) }\end{array}$ & $\begin{array}{l}\text { own FaMo } \\
\text { own MoMo }\end{array}$ & FaFaBrWi & $\begin{array}{l}\text { FaFaSi; FaMoSi; MoMoSi; } \\
\text { MoFaSi }\end{array}$ \\
\hline $\begin{array}{l}\text { iungin } \\
\quad \text { (grandchild) }\end{array}$ & own $\mathrm{ChCh}$ & $\begin{array}{l}\text { BrSoCh } \\
\text { FaBrSoSoCh }\end{array}$ & $\begin{array}{l}\mathrm{BrDaCh} ; \mathrm{FaBrDaChCh} ; \mathrm{MoBr}- \\
\mathrm{ChCh} ; \mathrm{MoSiChChCh} ; \mathrm{FaSi}- \\
\mathrm{ChChChCh}\end{array}$ \\
\hline $\begin{array}{l}\text { wa'engog } \\
\quad \text { (MoBr-SiCh) }\end{array}$ & $\begin{array}{l}\mathrm{MoBr} ; \mathrm{MoBrWi} \\
\text { (ms) SiCh }\end{array}$ & - & - \\
\hline $\begin{array}{l}\text { gidi ni m'fen } \\
\text { (FaSiCh) }\end{array}$ & $\mathrm{FaSiCh}^{*}$ & $一$ & - \\
\hline
\end{tabular}

* FaSiCh maintains an aclive relationship with ego as gidi ni m'fen, not as Mo or Fa.

** FaSi maintains an active relationship with ego but not as "mother" and without terminological differentiation.

The rules of reference bring the kinship terminology into line with the structure of the tabinau. They do this by further subdividing the terminological categories into active, potentially active and inactive relationships. This reduces the scope of the terms so that they apply differently to the different functional groupings. Ego maintains active relationships with members of his family of orientation and his family of procreation. He maintains potentially active 


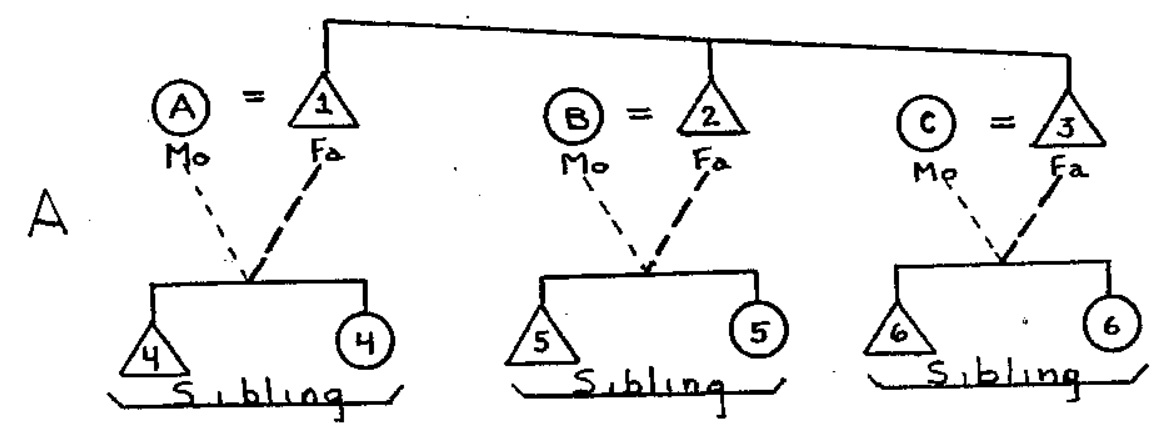

relationships with all the remaining members of his tabinau. All others are either terminologically distinguished from members of ego's own tabinau or, where they are not terminologically distinguished, are in inactive relationships. ${ }^{6}$ The structure of the tabinau is thus reflected not in the terminological system alone, but in the terminology as it is applied according to the rules of reference.

The ways in which ego's own nuclear families are distinguished from, but related with other nuclear families in his own tabinau, and the way in which the discreteness and importance of the nuclear family are stressed in the kinship system merit special attention, since these appear to be some of the special functions of the rules of reference.

Rules 2 through 6 of the rules of reference are especially pertinent here and may be briefly recapitulated and summarized in one diagram (Diagram III).

If a tabinau is assumed to be made up of three brothers and their wives and children, brothers 1,2 , and 3 , age-ranked in that order, and wives $A, B$, $C$, as in Diagram IIIA, then the lines of relationship which are seen on the charts define the persons who will be referred to by their kinship terms and who stand in active kinship relationships with each other. Children 4 will refer to $\mathrm{A}$ as mother, 1 as father, and each other as siblings. Children 5 will refer to $B$ as mother, 2 as father, and each other as siblings. Similarly for children 6 . Brother 1 will refer to A as spouse, 2 and 3 as siblings, and children 4 as "my children"; brother 2 will refer to B as spouse, brothers 1 and 3 as siblings, and children 5 as "my children." Similarly, brother 3. In Diagram IIIA, man 1 occupies the status of "leader of the tabinau," and 2 and 3, being younger than he is, regard him as "like a father" and he regards them as "like by children."

In Diagram IIIB, the oldest brother and head of the tabinau has died and been replaced by the next oldest brother, 2. As the diagram indicates, woman A has married the surviving younger brother 2 (optional levirate) and children 4 now refer to man 2 as father, continue to refer only to woman A as mother, and now include children 5 among their siblings. Children 5 continue to refer to 2 as father, $B$ as mother, but now include children 4 in their reference to siblings. Brother 3 and his wife $C$ and their children 6 have not been affected; children 6 still refer only to 3 as father, only to $C$ as mother, and only to each other as siblings.

In Diagram IIIC, brother 2 has died and the new head of the tabinau is surviving brother 3 . Both widows $\mathrm{A}$ and $\mathrm{B}$ have elected to remain in the tabinau and have married surviving brother 3 with his concurrence. Children 4 refer to 3 as father and $A$ as mother and include in their sibling reference children 5 and children 6 ; children 5 refer to 3 as father and $B$ as mother and include children 4 and 6 in their reference to siblings; children 6 refer to 3 as father and $C$ as mother, and include children 4 and 5 in their sibling reference. Reversing 
the perspective, 3 now refers to children 4, 5, and 6 as "my children," women A, B and C individually as "my spouse" or collectively as "my plural wives"; woman A only refers to children 4 as "my children" and 3 as "my spouse"; woman B refers to children 5 alone as "my children" and to 3 as "my spouse"; woman C refers only to children 6 as "my children" and to 3 as "my spouse."

From this account of the employment of the kinship terminology according to the rules of reference it is apparent that ego has a core of operative kinship relationships with members of his nuclear family (father, mother, sibling, spouse and child) which is sharply differentiated from those potentially active relationships which ego has with members of other nuclear families within his own tabinau.

Ego's potentially active relationships thus constitute a reservoir of potential mothers, fathers and siblings contained within the boundaries of ego's own tabinau. From this reservoir replacements are drawn in age-ranked order to fill statuses made vacant by death or divorce. Only the head of the tabinau is without an active mother or father. ${ }^{7}$

By thus relating ego's nuclear family with the other nuclear families in his tabinau as a core group differentiated from but imbedded in a reservoir from which replacements are drawn in an age-ordered manner, ego's nuclear family relationships receive the greatest possible emphasis.

Another element which contributes to the emphasis on the nuclear family is the confinement of kinship terms to situations of reference but not of address. That is, ego's relations with each member of his nuclear family proceed under the linguistic rubric of a personal name and not a kinship term. ${ }^{8}$

I suggest that one important function of the use of kinship terms as forms of address is in imposing on the situation a kind of sanction which enforces of address is in imposing on the relationship. This is so because the kinship term symbolizes a normatively defined relationship; that is, it stands for a specific way each person should behave toward the other. The employment of personal names, however, as forms of address permits the relationship wider latitude in that the nature of what the relationship should be is not directly specified. Thus a man will, in certain societies, attempt to enforce an obligation on another by invoking their kinship bond. He does this by using the appropriate kinship term as a form of address: "Brother, I need your help. ..."

On the other hand; those relationships in our society, for instance, which are most loosely defined, which tend toward equality in relationship, where the qualities of the person as a person are held to be most important and where formalistic considerations are confined to a minimum tend to be the relationships in which kinship terms are rarely if ever used as forms of address: husband-wife, uncle to nephew (but not vice versa), father to son (but not vice versa), sibling to sibling, and, somewhat less often, perhaps, cousin to cousin. In our society the considerations of most importance, I believe, are those of formality and authority versus informality and equality. A man will address his son as "son" when he wishes to stress the age and wisdom differential between them, and when he gives advice and guidance which may not be entirely welcome. But a man usually addresses his son by his given name. Similarly, a son will minimize the formal imbalance of authority and respect by using terms like "dad" and "pop" and "pa" in preference to the formal kinship term "father," although he will not often presume to the level of informality and equality signified by the use of the personal name. Indeed, the changing nature of the relationship between father and son as the son grows up may be reflected in the change of term of address which the son uses. As a child, he uses a term like "father" or "daddy" both in address and reference, while in early adolescence, he may shift to some term of address like "pop" while the term of reference may become "my old man." The shift in kinship term parallels the beginnings of the son's efforts to emancipate himself from his family, and he does this in no small part by depreciating the authority of the father and minimizing the respect due him and symbolizing this depreciation appropriately, if painfully for the father.

I suggest that the fact that Yap kinship terms are not used as terms of address permits the relationship latitude to include considerations of a personal nature. Considerations of personality and temperament and the nature of the relationship which is specific to the particular pair involved, are permitted to attain an importance that would be minimized were the relationship to be guided by the enunciation of the symbol stressing its strict social definition.

Thus by virtue of the fact that kinship relationships within the nuclear family are focused onto one mother and one father and not diffused among a group of persons occupying those statuses, and by virtue of the latitude which is permitted for the development of considerations of a personal sort, the depth and intensity of these relationships are increased, further stressing, for ego, the importance of his own nuclear family.

Not only within the nuclear family are kinship terms confined to situations of reference. No kinsman, irrespective of his status, is addressed by a kinship term, and the question of the meaning of this, in the light of the hypothesis on the nuclear family, necessarily arises. I suggest that the meaning remains the same as in the case of the nuclear family. Where the use of a kinship term serves as a symbol for the normative definition of the relationship, the absence of that symbol permits the relationship to become established on other grounds. The use of the kinship term defines the situation as one of kinship of a particular sort; the omission of the kinship term permits the situation to be defined without that restriction.

In the case of those relationships which ego has with persons in potentially active or inactive statuses, the invocation of a kinship term as a form of address 
would be plainly contradictory. That is, for ego to address a person as "father" would define the relationship between them as that of father and child, and so guide their actions. Yet by the Yap rules of reference a person classified as father in inactive status may not act as a father but only as a generalized ing specially defined role. Hence the fact the person in in active status is addressed by his personal name and not by any kinship term is congruent with his undifferentiated role.

The final element which must be noted in discussing the emphasis which is placed on the nuclear family as a unit in the Yap kinship structure is that this emphasis is not equally distributed throughout all the relationships but is instead selective. The relationships of father-child and mother-child are especially reinforced, while those of sibling-sibling and husband-wife receive no special structural reinforcement.

The reinforcement of the parent-child relationship derives in large part rom two considerations. That is, except in the case of the head of the tabinau, the statuses of mother and father in active relationship with ego are always the second consideration is filled by some person and are never left vacant. The second con one person at one time.

The effect of confining the parental status to only one person at one time is to concentrate all meaningful aspects of that relationship as it is socially dethe diffusion of emotional response among a group of mothers which has been described for the Navajo and Samoans, for instance, is not possible in Yap.

The fact that special structural provisions automatically take care of almost every case of a broken parent-child relationship, while no structural most every case of a broken parent child relationship whibling relationprovision is made for repairing breaks in either the conjugal or sibling relationship, gives these relationships quite different structural positions. The parentchild relationship is structurally central; the sibling relationship and the conjugal relationship are structurally more peripheral, although by no means unimportant.

It should be pointed out that the effect of the reservoir system is neither to strengthen the tabinau at the expense of the constituent nuclear families, nor to strengthen the constituent nuclear families at the expense of the tabinau. A status is not lost by one group and gained by another; it is rather that the nex closest kin assimilates the disrupted nuclear family into his own nuclear family closest kin assimilates the disrupted nuclear fan man whe takes over the father role of his deceased brother toward the deceased brother's children, and the husband role toward the deceased brother's wife, does not thereby relinquish or abandon those roles with respect to his own nuclear family. What he does, in effect, is to expand his own nuclear family by incorporating the children into it and assume the husband's responsibilities toward his new wife as well as retaining them toward his own wife.

Actually, two reservoirs exist from the point of view of any nuclear family member; that of the tabinau members and that of traceable kin who are nontabinau members. If the first reservoir of tabinau members is empty, the second, more remote reservoir of non-labinau members may be drawn upon in the same way. Remote fathers and mothers, ordinarily in inactive relationships, are drawn upon in this way only where the gravity or formality of the situation makes an intermediary indispensable, when they usually enter into an active relationship with ego only for the duration of the particular situation.

The remaining kin group which requires discussion is the matrilineal clan. This group, the genung, is distinguished by the fact that it does not constitute a corporate group even in the limited sense that the tabinau does. The role of the tabinau in Yap social structure is specifically defined and clear cut. It is the small cohesive, localized, manageable land holding and inheriting unit with distinct political functions within the village. It is the building block from which the village, the district and alliance are constructed. It is defined as in cluding those persons who are by descent or marriage associated with a parcel of land-the highest value expressed in Yap social structure. The matrilineal clan is ultimately oriented in large part to this same value, but in a very differ ent way. It is both geographically and functionally diffuse. Except for the specificity of the rule governing membership (matrilineal descent) and the rule of exogamy, it has but a few highly diffuse but none the less pervasive and important functions. It constitutes a group of persons who regard themselves as related, as closer than non-kin, and hence the first line beyond the tabinau where kin can be called on for whatever purpose. Amplifying the diffuseness and pervasiveness is the notion that the individual's membership in a particular group is a secret.

Thus, although the Yap genung is a matrilineal clan, it lacks the corporate character usually associated with unilineal kin groups. It is not segmented into functional lineages. It lacks formal organization of any degree of complexity. It is less a "group" than an "aggregate," and it does not constitute a distinctive segment of the social structure, as the tabinau does. It is, in short, a mode of relationship for any given ego rather than a system of relations.

In the light of these facts it is reasonable that the terminological system does not distinguish or group matri-kin as a unit, as is often true in societies where Crow type cousin terminology prevails. Instead the emphasis is placed on certain distinctive relationships of a matrilineal order which orient ego toward that mode of relationship in general without treating the matrilineal groups as unified or unitary.

Thus the fact that the kinship terminology does not designate the matri- 
lineal kin group as a corporate unit (in contrast to the Hopi (Eggan, 1949, pp. 121-144), for instance), is congruent with the non-corporate character of this group. The fact that matrilineal bonds are socially recognized is congruent with the recognition of specially differentiated terminology along close matrilineal lines.

\section{CONCLUSION}

If the structure of the Yap kin groups is treated as given, certain distinctive problems arise when the relationship of the terminological system to these groups is examined.

The Yap tabinau is so structured that the nuclear family relationships and the nuclear family as a group are given marked emphasis while embedded in a matrix which is essentially unilineal in character. In certain important respects these two groups - the nuclear family and the unilineal kin groupare incompatible in nature. The fact that the nuclear family is sociologically indispensable sets a limit on the adaptation which can be made to this fact. The normal adaptation thus tends toward one or the other extreme of imbalance; at one pole the nuclear family becomes paramount and by its weight precludes any coherent, strongly corporate extended grouping, while the other pole is represented by the situation in which the nuclear family tends to be pole is represented by the situation in which the nuclear family tends point of non-existence. (This applies equally to the extended, family of course.)

The nature of the incompatibility between the nuclear family and the lineage lies in the fact that the lineage rests on the principles of the unity and solidarity of the sibling group (Radcliffe-Brown, 1941, pp. 7-9) while the nuclear family as a group rests on the premise that siblings are not a unit composed of socially equivalent elements. That is, either ego treats his father and his father's siblings as socially equivalent and one solidary unit, and he is committed to solidarity with this group as against other groups, or he differentiates his father from his father's siblings and treats them as two distinct units with different relationships appropriate to each. The degree to which one of these alternatives is stressed is proportional to the degree to which the other is precluded.

The situation which obtains in the nuclear family is one in which ego differentiates his father from his father's siblings, and his mother from his mother's siblings. His solidarity with his own two parents is differentiated from his solidarity with his parents' siblings. Part of the differential solidarity derives from the relatively greater intensity of ego's relationship. with his own father and his own mother as compared with his relationship to his father's siblings and his mother's siblings. Hence the solidarity of the nuclear family is achieved at the expense of the solidarity of the wider grouping of father and his siblings and/or mother and her siblings.

In the lineage, on the other hand, ego treats father and his siblings as a unit with relatively slight differentiation between members of that unit. Any priority which ego gives to his relationship with his own father as against his father's siblings minimizes the solidarity between him and his father's siblings, and maximizes the differentiation of father's siblings from father. Hence ego tends, in a lineage, to minimize the priority of his relationship with his own father. Correspondingly the solidarity between father and his siblings and between ego and the group of father's siblings (including father) is maximized, relatively speaking, at the expense of the particular relationship between ego and his own father. It is as a function of the maximization of the solidarity between siblings that solidarity in the conjugal relationship is correspondingly minimized. Hence the frequent observation of either brittle marriage (as among the Hopi (Eggan, 1949, pp. 139 and 142)), soluble conjugal bonds but juridically stable marriage (as among the Nuer (Evans-Prichard, 1950, pp. 94, 95, 116$117,120)$ ), or enforced stability of marriage (as among the Zulu (Gluckman, 1950 , pp. 166-206)), as a corollary of lineage systems.

If the Yap tabinau is structured as a series of discrete emphasized nuclear families embedded in a patrilineal lineage, the problem of how this potentially contradictory structure is maintained requires some explanation. The answer seems to me to lie precisely in the facts which have been set forth. The solidarity and unity of the nuclear family are maintained by concentrating ego's relationships within his nuclear family, and this concentration clearly is achieved at the expense of lineage solidarity. On the other hand, the unity of the lineage does not depend on its internal solidarity alone. The unity of the lineage depends on a minimal degree of internal solidarity and on the fact that social units outside the lineage treat it as a unit. In the case of the Yap tabinau the existence of the lineage depends less on the solidarity of the sibling group than on three features of its structure. (1) It is treated by all outside groups as a unit; (2) its position as a unit can be maintained primarily through the actions of one man, the leader of the tabinau, and (3) the nuclear family is related to the tabinai as a reservoir from which replacements can be drawn in support of the nuclear family. Areas of activity are so segregated for any tabinau member that conflict between his solidarity with his tabinau and his solidarity with his nuclear family are minimized.

It is precisely the relationship between the tabinau and the nuclear family as a reservoir to the primary unit which is maintained by the rules of reference in conjunction with the system of kinship terminology. On the one hand a lineage type of kinship terminology classifies groups of persons into certain crucial statuses defined in terms of the nuclear family (fathers, mothers, siblings), while on the other hand the rules of reference divide them into active relationships (nuclear family members), potentially active relationships (reservoir tabinau), and inactive relationships. If the relationship between the tabina $u$ as reservoir and the nuclear family as primary unit is indeed the crucial 
relationship in maintaining the compromise between the nuclear family and the lineage, then one of the important functions of the rules of reference is to provide for the emphasis on the nuclear family while maintaining a lineage type of terminology admirably. suited to the lineage features of its structure.

On the basis of this analysis I would venture the following hypothesis: Given kin groups which compromise between lineage type structure and emphasis on the nuclear family, it is impossible for any terminological system alone to symbolize adequately both the kinds of relationships and the kinds of groups necessarily consequent on that compromise. When, as in Yap, the nuclear family is so valued that it is differentiated as a separate unit and so maintained, there must be some way of symbolizing that differentiation. Terminological differentiation of the bifurcate collateral sort admirably differentiates the nuclear family, but it does so to the point where an uncle can ever substitute mother. Instead the never become a substitute father nor an aunt a substitute mother. Instead the orphan and the step-parent become the relations consequent on a parents death. Conversely, bifurcate merging terminology does not adequately differentiate ego's nuclear family from collateral nuclear families. Generation type terminology shares the same disabilities in this respect, while lineal type terminology is functionally equivalent in this respect to bifurd terminology. It follows, I believe, that terminological differentiation alone is the specifications of this particular combination not functionally suited to the specifications of this particular combination some device which is functionally equivalent to the Yap rules of reference must be employed if this type of compromise structure is to be maintained; that is, some differentiating mechanism which takes account of death by providing a substitute for the deceased when and as he is needed, but not before.

In conclusion, I would raise the problem of the stability of a system such s that of Yap. From more than one point of view this system seems to carry on in the face of a host of strains, only a few of which have been analyzed here. Among the most prominent strains which might be deduced from this report are the following: Crow type cousin terminology in the presence of patrilinea kin groups, weak matrilineal clans in the presence of powerful patrilineal lineages, the nuclear family emphasized in the presence of functional patrilineal lineages, and structurally important lineages of minimal solidarity. History, as is so frequently the case where non-literate peoples are concerned is not easy to reconstruct. In this case particularly I should hesitate to use history reconstructed on the basis of hypotheses about the kinship system. Internal evidence suggests that the system is well integrated, and since this is seldom achieved overnight, one might venture to assume that the system has been in operation for at least 100 years or more. This venture is supported by the fact that although the early literature is scanty, it contains no hint of a different system. Further, with all the consciously directed efforts of the missionaries, the Spanish, German and especially the Japanese administrators, and with all the changes both social and economic which have occurred since the late 1800 's, every evidence suggests that the system has remained essentially unchanged over this period. Finally, depopulation, which is estimated to have begun at least one hundred years ago, might have affected the system or it might not. The emphasized nuclear family might be seen as a response to a shrinking lineage. On the other hand, if the nuclear family had been emphasized before depopulation began, it might equally well be seen as a system peculiarly suited to withstand the ravages of depopulation. There seems to be no way of telling whether the nuclear family did or did not change its structural position with depopulation. What little evidence there is tends to point to a relatively stable system, at any rate no more unstable than most other systems we tend to regard as stable. I hope to follow out the implications of this in a later publication.

HARVARD UNIVERSTTY,

Cambridge, Massachusetts

NOTES

${ }_{1}$ Although the relationship of a young woman resident (mispil) in the young men's club house and the men of the club house is defined by the Yap as one of marriage, it does not constitute a marriage by our definition since the young woman, should she become pregnant, is retired from the club house as the wife of only one of its members.

2 The man who is married to mother at the time of her pregnancy and delivery, or where divorce occurs during pregnancy, the man married to mother at the time of her divorce.

${ }^{3}$ Except, of course, when the term fakag is used in the sense of an animate possessive, e.g. "my dog."

4 Rules 2 through 7 correspond to what Kroeber $(1909$, p. 79) called "The condition of life of the person through whom relationship exists." Rules 2, 5 and 6 correspond to the criterion of "decedence" proposed by Murdock (1949, p. 106). Kroeber's usage describes the Yap situation more comprehensively than does Murdock's, but neither these workers, nor any other as far as I know, has analyzed this device at any length. Because this is the first such analysis, and because the analysis is confined for the present to the Yap data alone, I have hesitated to apply either Kroeber's or Murdock's names for these devices. Their names derive from other data which may or may not be of the same order as these Yap data. I hope to present a comparative analysis of these devices in the near future.

"This is a concrete example of what Radcliffe-Brown has termed "The Principle of the Unity of the Lineage Group." (Radcliffe-Brown, 1941, p. $10 \mathrm{ff}$.)

6 Except for mother's parents and daughter's children.

${ }^{7}$ However, the head of the tabinau has a pool of tabinau ghosts who stand in precisely the ame kind of parental relationship to him which he stands to his juniors, and toward whom he takes precisely the same kind of junior's or child's role as his juniors and children take toward him. The head of the tabinean entreats the ghosts to mediate with other supernaturals on his behalf and on behalf of his tabinau. The most important of these ghosts are often his own deceased mother and father.

8 Since no one, to my knowledge, has adequately analyzed the use of terms of address as distinct from terms of reference, the paragraphs which follow are necessarily hypotheses which remain to be tested. 